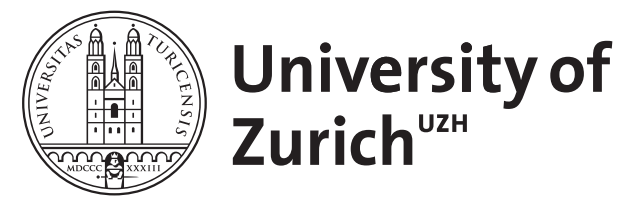

\title{
Surfactant effects on amyloid aggregation kinetics
}

\author{
Friedman, R ; Caflisch, A
}

\begin{abstract}
There is strong experimental evidence of the influence of surfactants (e.g., fatty acids) on the kinetics of amyloid fibril formation. However, the structures of mixed assemblies and interactions between surfactants and fibril-forming peptides are still not clear. Here, coarse-grained simulations are employed to study the aggregation kinetics of amyloidogenic peptides in the presence of amphiphilic lipids. The simulations show that the lower the fibril formation propensity of the peptides, the higher the influence of the surfactants on the peptide self-assembly kinetics. In particular, the lag phase of weakly aggregating peptides increases because of the formation of mixed oligomers, which are promoted by hydrophobic interactions and favorable entropy of mixing. A transient peak in the number of surfactants attached to the growing fibril is observed before reaching the mature fibril in some of the simulations. This peak originates from transient fibrillar defects consisting of exposed hydrophobic patches on the fibril surface, which provide a possible explanation for the temporary maximum of fluorescence observed sometimes in kinetic traces of the binding of small-molecule dyes to amyloid fibrils.
\end{abstract}

DOI: https://doi.org/10.1016/j.jmb.2011.10.011

Posted at the Zurich Open Repository and Archive, University of Zurich ZORA URL: https://doi.org/10.5167/uzh-51369

Journal Article

Accepted Version

Originally published at:

Friedman, R; Caflisch, A (2011). Surfactant effects on amyloid aggregation kinetics. Journal of Molecular Biology, 414(2):303-312.

DOI: https://doi.org/10.1016/j.jmb.2011.10.011 


\title{
Surfactant effects on amyloid aggregation kinetics
}

\author{
Ran Friedman ${ }^{a b *}$ and Amedeo Caflisch ${ }^{a *}$ \\ ${ }^{a}$ University of Zürich, Department of Biochemistry, Winterthurerstrasse 190, 8057 Zürich, \\ Switzerland ${ }^{b}$ Linnceus University, School of Natural Sciences, 39182 Kalmar, Sweden. \\ *corresponding authors, e-mail: ran.friedman@lnu.se, caflisch@bioc.uzh.ch
}

\begin{abstract}
There is strong experimental evidence of the influence of surfactants (e.g., fatty acids) on the kinetics of amyloid-fibril formation. Yet, the structures of mixed assemblies and interactions between surfactants and fibril-forming peptides are still not clear. Here, coarse-grained simulations are employed to study the aggregation kinetics of amyloidogenic peptides in the presence of amphiphilic lipids. The simulations show that the lower the fibril-formation propensity of the peptides the higher the influence of the surfactants on the peptides self-assembly kinetics. In particular, the lag phase of weakly aggregating peptides increases because of the formation of mixed oligomers, which are promoted by hydrophobic interactions and favorable entropy of mixing. A transient peak in the number of surfactants attached to the growing fibril is observed before reaching the mature fibril in some of the simulations. This peak originates from transient fibrillar defects consisting of exposed hydrophobic patches on the fibril surface, which provide a possible explanation for the temporary maximum of fluorescence observed sometimes in kinetic traces of the binding of small-molecule dyes to amyloid fibrils.
\end{abstract}

Keywords: molecular dynamics, coarse-grained simulations, globulomers, amyloid fibrils, micelles, Alzheimer's disease 


\section{Introduction}

Amyloid-related diseases are cureless illnesses whose major hallmark is the aggregation of peptides or misfolded proteins. Despite intense research efforts it is still not clear if the toxic species are the insoluble fibrils or soluble oligomeric species, or both. Soluble oligomers have been linked with disease progression in Alzheimer's disease [1, 2, 3], Parkinson's disease [4, 5], type II diabetes mellitus [6] and other amyloid-related diseases [7]. A stable, soluble aggregate of the Alzheimer's A $\beta_{1-42}$ peptide has been observed upon incubation in the presence of free fatty acids or sodium dodecyl sulfate (SDS) [8]. This oligomeric form, termed globulomer, was found to induce neuropathologies by suppressing the synaptic activity [9]. Globulomers seem to be formed off-pathway, i.e., independent of fibril-formation [10]. Structural studies involving atomic force microscopy and nuclear magnetic resonance suggested that there are two main species of $\mathrm{A} \beta$ globulomers, with $\mathrm{N}=2-6$ or $12-16$ peptides per aggregate [11], but fine details on the structures of those are not available. Radiolabeled detergent and size exclusion chromatography experiments indicate approximately one SDS molecule per peptide, but the shape of globulomers and probably also the number of bound molecules depend on surfactant concentration [8]. It should be noted that the term globulomer is sometimes used in the literature as an acronym for globular oligomers, irrespective to the presence of surfactants. Here, we use this term only when we discuss oligomers that are made of peptides and surfactants together.

Following the identification of disease-related soluble oligomers generated through interactions between amyloidogenic (poly)peptides and fatty-acids or other surfactants [4, 8], few structural and biophysical studies were aimed at characterizing these interactions. SDS and several types of fatty acids induce formation of $\beta_{2}$-microglobulin fibrils, which may have clinical relevance for $\beta_{2}$-microglobulin related amyloidosis [12]. Furthermore, binding to detergent micelles promote conformational transitions in the islet amyloid polypeptide (IAPP) [13] and A $\beta$ peptide $[14,15]$. Soluble oligomers can also be formed from 
a mixture of equine-lysozyme and oleic acid by ion-exchange chromatography. These oligomers are cytotoxic and interact with the thioflavin $\mathrm{T}$ dye, similar to amyloid fibrils, although they are not fibrillar [16].

Only few experimental studies deal with kinetic and structural aspects of surfactant-induced amyloid peptide oligomer formation. Computational studies at different levels of approximation of multipeptide systems have been performed to help the interpretation of the experimental data on amyloid aggregation [17, $18,19,20,21,22,23,24,25,26]$. Yet, as of today no simulation study of the effects of surfactants on amyloid aggregation has been reported. Here we use a simple model of an amphipathic peptide (coarse-grained phenomenological) [27, $28]$ to study the aggregation of amyloid peptides in the presence of surfactant molecules. More explicitly, the simplified peptide model can adopt two states, amyloid-prone $(\beta)$ and amyloid-protected $(\pi)$, where the free energy difference between the two states is the only free parameter, $\mathrm{dE}=\mathrm{E}_{\pi}-\mathrm{E}_{\beta}$ (Figure 1A). The lower (more negative) the value of $\mathrm{dE}$, the less amyloidogenic is the peptide, and variations of $\mathrm{dE}$ reproduce the broad range of experimentally observed pathways and kinetics of aggregation [27, 28] as well as fibril polymorphism [29]. Using this very simple model enables the simulation of a system that can form soluble oligomers as well as fibrils. Langevin simulations at $310 \mathrm{~K}$ are performed here with 125 copies of the simple peptide in the presence of 0,500 , or 1000 surfactant molecules approximated by a three-bead model [30]. The simulations indicate that the surfactant molecules have a strong influence on the early phase of aggregation, particularly for peptides with low amyloidogenic tendency.

\section{Results and Discussion}

In the following, the terms globulomer and mixed micelle are used for mainly spherical (i.e., non-fibrillar) aggregates consisting of a mixture of peptides and surfactants molecules. In contrast, the term fibril is used for aggregates whose ordered arrangement (i.e., one-dimensional periodicity) is due solely to the selfassembly of peptides. The peptide fibrils can host a variable number of surfac- 
tants located mainly at exposed hydrophobic surface patches.

\section{The influence of surfactants depends on the peptide amyloidogenic tendency}

The self-assembly kinetics can be analyzed by monitoring the temporal evolution of the number of peptides (out of 125) in the largest cluster, i.e., largest globulomer or fibril. In the absence of surfactants, all peptide models form fibrils within $1 \mu \mathrm{s}$ with a very short lag phase (Figure 2, dotted lines). At a surfactant:peptide ratio of 8:1, the fibril formation kinetics of peptides with $\mathrm{dE}=-1.5 \mathrm{kcal} / \mathrm{mol}$ are almost unaffected, whereas already at a ratio of $4: 1$ the ordered self-assembly of peptides with $\mathrm{dE}=-2.25 \mathrm{kcal} / \mathrm{mol}$ is significantly slower mainly because of a longer lag phase (Figure 3). Moreover, for lowamyloidogenic peptides ( $\mathrm{dE} \leq-2.0 \mathrm{kcal} / \mathrm{mol})$ there is no fibrillation at all within the simulation length of $2 \mu \mathrm{s}$ at a surfactant:peptide ratio of 8:1, but instead the formation of globulomers of about 40 peptides. These simulation results show that at a 4-fold or 8-fold molar excess of surfactant the inhibition of fibrillation depends strongly on the amyloidogenic propensity of the peptide.

It is interesting to compare the influence of surfactants on peptide aggregation with the effect of inert molecules (crowders) which has been studied recently by using the same simplified peptide model [31], a simplified analytical model [32] and an atomistic model [33]. For peptides with low amyloidogenic propensity, the fibril formation kinetics are slowed down in the presence of surfactants due to favorable surfactants/peptides interactions which result in a longer lag phase (Figure 2). In contrast, the rate of fibril formation increases by raising the concentration of inert crowders [31]. Apparently, the crowders effectively reduce the volume available to the peptides, thereby enhancing their probability to nucleate $[31,33]$. Common to both surfactants and crowders effects is the strong dependence on the amyloidogenic potential of the peptide model (i.e., $\mathrm{dE}$ value) and in particular the almost negligible influence in the high amyloidogenicity regime (Figure 2 of this work and Figure 5 of [31]).

Recently, Dahse et al. have reported experimental measurements of the lagphase time and elongation rate constant for the aggregation of $50 \mu \mathrm{M} \mathrm{A} \beta_{1-40}$ in 
the presence of various concentrations of dihexanoylphosphatidylcholine (DHPC) corresponding to DHPC:A $\beta_{1-40}$ ratios ranging from 8:1 to 350:1 [34]. At low DHPC concentrations (i.e., DHPC:A $\beta_{1-40}$ ratios up to about 50:1) the lag phase and elongation rate do not vary significantly by increasing the amount of DHPC. The almost constant elongation rate is in agreement with the simulation results. On the other hand, the strong variation of the lag phase observed in the simulations might be due to the different concentration ratios (up to 8:1 in the simulations and 50:1 in the experiments) and/or different relative size of surfactant and peptide.

The morphology of globulomers and fibrils in the presence of surfactants

The metastable and final aggregates contain a mixture of peptides and surfactants under all conditions used in the simulations (Table 3). The morphology of these aggregates depends strongly on the peptide amyloidogenicity and molar excess of surfactant (Figure 4). In the low-amyloidogenic regime ( $\mathrm{dE} \leq-$ $2.0 \mathrm{kcal} / \mathrm{mol}$ ) and 8-fold molar excess of surfactants, globulomers of relatively constant size emerge as the final product. These mixed aggregates consist of about 40 peptides, and about four surfactant molecules per peptide (Table 3). Both the peptides and surfactants have their hydrophobic beads oriented inwards and hydrophilic beads facing the bulk, as in ordinary micelles. The peptides in these aggregates are predominantly in a non aggregation-prone conformation, suggesting that favorable van der Waals interactions between peptides and surfactants hinder fibril formation. Notably, micellar aggregates, made of surfactants and peptides have been observed experimentally in mixtures of proteins with SDS $[35,36]$. At a surfactant:peptide ratio of 4:1, globulomers are formed with a relatively small number of surfactant molecules (Figures 3, bottom and 4, bottom). These globulomers increase significantly the length of the lag phase. The formation of mixed assemblies is due to the similar size of the peptide and surfactant models which are both amphipathic. In other words, the mixing entropy of the surfactants and peptides is more favorable for heterogeneous- than for self-assembly. It is interesting to note in this context 
that mixed clusters [37] have been observed in experiments performed with two types of small surfactants due to the favorable entropy of mixing [38]. Calculations of entropy changes from molecular dynamics simulations are computationally and theoretically demanding, and have hitherto performed mainly on systems such as ion and ligand binding to proteins or conformational changes in proteins $[39,40]$. Therefore, we discuss the mixing entropy only at a qualitative level. Mixing the surfactant and peptides can yield one of three scenarios: (1) a system of mixed micelles (2) a system with fibrils and amorphous surfactant aggregates forming two different phases (3) fibrils coated with surfactants. The first scenario is favored over the second owing to the entropy of mixing whereas the third is favored by enthalpy for peptides with high amyloidogenicity.

The analysis of the structures of the fibrils grown in the presence of surfactants (supplementary Figure S1) shows that the main fibrillar morphologies are essentially identical as in previous simulations without surfactants [29]. This observation can be explained by the location of the surfactants which are almost exclusively found on the surface rather than inside the fibril because of the differences in the intermolecular interactions. The van der Waals energy between pairs of hydrophobic beads on different peptides (minimum value of -1.3 $\mathrm{kcal} / \mathrm{mol}$ ) is more favorable than between hydrophobic beads on peptide and surfactant (minimum of $-1.02 \mathrm{kcal} / \mathrm{mol}$ ). Moreover, only the peptide-peptide interactions have an electrostatic component, which stabilizes the fibrils when the inner core is composed of peptides only. At 4:1 surfactant:peptide ratio, the fibrils adsorb only few surfactant molecules. At 8-fold molar excess of surfactant, the largest aggregates contain both a fibrillar part consisting mainly of peptides and amorphous aggregates of surfactants. Despite the differences in the simulated system and details of the model, the adsorption of the surfactants to the fibril is reminiscent of the spontaneous coating of the hydrophobic patches of a membrane protein immersed in detergent solution observed previously in explicit-solvent MD simulations [41]. 
Transient peak of surfactants attached to the growing fibril

The time series of the number of surfactants show a transient maximum in about half of the runs with a 4:1 surfactant:peptide ratio (Figure 5 and supplementary Figures S2 and S3). In other words, a smaller number of surfactants are attached to the mature fibril than to the growing fibril because of the transient nature of exposed hydrophobic surface patches on the latter. This simulation result is consistent with the peak in fluorescence of the amyloid indicator dye thioflavin $\mathrm{T}$ which is sometimes present before the plateau region in measurements of fibril formation kinetics (as an example, see Figure 4 of Ref. [42]). Since the coarse-grained model is very simple and the peptide-surfactant interactions are only van der Waals, the transient peak does not necessarily require specific binding of the surfactants. The peak rather originates from unspecific binding to transient defects of variable shape and size on the surface of the growing fibril (see inset in the middle of Figure 5 as an example). In this context, it should be noted that even monomeric $\beta_{2}$-microglobulin can bind thioflavin $\mathrm{T}$ and increase its fluorescence [43]. Thus, the simple model used in the simulations provides a possible explanation for a counter-intuitive experimental observation. Analysis of the time series of the individual intermolecular contributions confirms that surfactant-peptide interactions become less favorable upon fibril formation while peptide-peptide interactions stabilize the fibrillar state (Figure 6). The surfactant-surfactant interactions and their variation during fibril formation are negligible and do not contribute to the stabilization of globulomers and fibrils. Note that as mentioned above, both peptide-surfactant interactions and entropic contributions favor the formation of mixed micelles which are metastable because of the strong enthalpic stabilization of the mature fibril.

\section{Conclusions}

The comparative analysis of coarse-grained simulations of peptide aggregation in the presence and absence of surfactants suggests three main conclusions. 
First, the influence of surfactants on the peptide self-assembly kinetics depends strongly on the fibril formation propensity of the peptides. The length of the lag phase increases significantly for peptides with low amyloidogenic tendency because of the formation of mixed micelles which is a consequence of the hydrophobic effect and entropy of mixing. Fibril nucleation takes longer from a mixed micelle than from an oligomer consisting exclusively of peptides because the number of peptides in the mixed micelle is smaller than the nucleus size for fibril formation and/or the surfactants hinder the formation of a homogeneous (i.e., peptide only) nucleus within the mixed micelle. As an example, there are about 20 peptides in the mixed micelle at $\mathrm{dE}=-2.25 \mathrm{kcal} / \mathrm{mol}$ (Table 3 ) while the nucleus for fibril formation consists of about 27 peptides [27].

Second, the structural polymorphism of the mature fibrils is essentially identical in the presence and absence of surfactants. This observation might be a consequence of the coarse-grained model used in this study which is very simple and lacks electrostatic interactions between peptides and lipids. Therefore, the model better represents nonionic surfactants than lipids with several charged groups. It cannot be excluded that specific electrostatic interactions between peptides and ionic lipids (e.g., in zwitterionic surfactants) might shift the fibril polymorphism towards a few privileged fibrillar structures.

Third, there is sometimes a transient peak of the number of surfactants attached to exposed hydrophobic surface patches on the growing fibril. This simulation result can be compared with the transitory maximum occasionally observed in experimentally measured kinetic traces, e.g., of the amyloid indicator dye thioflavin $\mathrm{T}$. It is likely that the non-polar groups of thioflavin $\mathrm{T}$ are mainly responsible for association to protofibrils and fibrils rather than its positively charged thiazole ring, particularly for amyloid fibrils of peptides devoid of negatively charged side chains. Thus one possible explanation of the transient peak is the unspecific binding dominated by surface complementarity of nonpolar groups. Moreover, the growing of isolated fibrils can be responsible of the peak which does not necessarily require the association of two or more growing fibrils into transient assemblies with additional binding pockets. In conclusion, 
the coarse-grained simulations indicate that very simple models can shed light on experimental data that are difficult to interpret because important aspects of molecular interactions and aggregation are not accessible by conventional kinetics measurements.

\section{Materials and methods}

\section{Coarse-grained Langevin dynamics simulations}

Simplified peptides. The phenomenological coarse-grained model of an amphipathic peptide is described in detail elsewhere [27, 28]. Simplified peptides consists of 10 beads and have a single degree of freedom with two main states (Figure 1A). Their conformation can be either aggregation-prone $(\beta)$ or aggregationprotected $(\pi)$, where the latter conformation is 64,39 , and 15 times more populated than the former depending on the value of $\mathrm{dE}=\mathrm{E}_{\pi}-\mathrm{E}_{\beta}=-2.25,-2.0$, and $-1.5 \mathrm{kcal} / \mathrm{mol}$, respectively (see Table 4 in the supporting information of Ref. [27]). Fibrils are stabilized by inter-peptide van der Waals interactions and inter-peptide dipole-dipole interactions. In the absence of surfactants, from about $80 \%$ (for $\mathrm{dE}=-2.25 \mathrm{kcal} / \mathrm{mol}$ ) to about $95 \%$ (for $\mathrm{dE}=-1.5 \mathrm{kcal} / \mathrm{mol}$ ) of the peptides are part of a single fibril in the final phase, at which there is an equilibrium between fibril and isolated peptides [27].

Coarse-grained surfactants. Surfactant molecules consist of three beads connected by two bonds (Figure 1B). A hydrophilic bead represents the head group and two hydrophobic beads represent the aliphatic tail. The surfactant model differs from lipid models used previously in two parameters (Figure 1): the minimum of the van der Waals energy of the two hydrophobic beads is less favorable and the radius of the hydrophilic bead is larger to enable the formation of amorphous aggregates. Using these parameters, 1000 surfactants simulated in a cubic box of $29 \mathrm{~nm}$ edge form amorphous aggregates that are qualitatively similar to those observed experimentally [44]. The average number of surfactants in the aggregates is $2.7 \pm 0.3$ at $310 \mathrm{~K}$. Micelles are not the main aggregate under these conditions, but can sporadically form. In simulations of more dilute solutions, 
i.e., 512 surfactants in a similar cubic box, micelles form the largest clusters but most of the surfactants exist as monomers. The scaling factor of the van der Waals interactions between peptides and surfactants is set to 1.0, i.e., scaling is not applied, in contrast with previous studies which focused on interactions of amyloid peptides with lipid bilayers [30, 45]. The aforementioned reduction in the strength of the van der Waals energy of the hydrophobic beads in the lipid model results in the spontaneous formation of mixed micelles in simulations started from monodispersed surfactants and peptides (see the Results section).

Limitations of the simplified coarse-grained model. The coarse-grained model that is used here to describe the peptides and the surfactants has several limitations. First, it is not able to account for the specific sequence of the peptides or describe the chemical composition of the surfactants. Rather, the physical properties of the peptides, as related to their ability to aggregate, are included in the dE parameter. The affinity of the surfactants to the peptides can be tuned, as done previously with lipids [45]. This parameter was not modified here owing to the lack of experimental reports on the interactions between different surfactants and amyloid peptides. Another limitation is the lack of formal charges in the lipids and surfactants. This is necessary to prevent artificial interactions in the absence of explicit solvent.

Simulation protocols. The amyloid aggregation simulations are started by randomly placing in a cubic box (of $29 \mathrm{~nm}$ edge) 125 peptide monomers (resulting in a concentration of $8.5 \mathrm{mM}$ ), and 0,500 or 1000 surfactant molecules (Table 2), so that the distance between any pair of molecules is larger than $0.5 \mathrm{~nm}$. The system is thereafter minimized, equilibrated and simulated by Langevin dynamics at $310 \mathrm{~K}$ using CHARMM [46, 47]. The bonds are constrained by the SHAKE algorithm [48]. Apart from the number of surfactants, the only parameter that is modified between simulations is $\mathrm{dE}$, the energy difference between the amyloid-protected and amyloid-prone conformations of the peptide in its monomeric state. Thus, the more negative the value of $\mathrm{dE}$, the lower 
the amyloidogenicity, i.e., the lower the tendency of the peptides to aggregate into fibrils. Multiple simulations are run for each value of $\mathrm{dE}$ and number of surfactants, where the initial velocities are set by different random seeds. For details on the simulations in the absence of surfactants see references [27, 28].

\section{Analysis of the trajectories}

Analysis of the simulations was carried out by routines available in Gromacs and home-written software, including a version of the Gromacs program g_clustsize modified by us to account for the structure and composition of the aggregates (available upon request). The WORDOM program [49, 50] was used to convert CHARMM trajectories to .xtc files which can be handled by Gromacs. All figures with molecular models were produced using VMD [51].

\section{Acknowledgement}

We thank Dr. Riccardo Pellarin for the analysis of the fibrillar morphologies and interesting comments to the manuscript. This work was supported by the NCCR Neural Plasticity and Repair of the Swiss National Science Foundation, the Research Program for young scientists of the University of Zürich, the Olga Mayenfisch Foundation, and the Holcim Foundation. R.F. is supported by startup grant from the Linnæus University. The simulations were carried out on the Schrödinger cluster of the University of Zürich.

\section{References}

[1] Y. M. Kuo, M. R. Emmerling, C. Vigo-Pelfrey, T. C. Kasunic, J. B. Kirkpatrick, G. H. Murdoch, M. J. Ball, A. E. Roher, Water-soluble abeta (n-40, n-42) oligomers in normal and Alzheimer disease brains, J Biol Chem 271 (1996) 4077-4081.

[2] W. L. Klein, G. A. Krafft, C. E. Finch, Targeting small Abeta oligomers: the solution to an Alzheimer's disease conundrum?, Trends Neurosci 24 (2001) 219-224. 
[3] M. N. Reed, J. J. Hofmeister, L. Jungbauer, A. T. Welzel, C. Yu, M. A. Sherman, S. Lesné, M. J. Ladu, D. M. Walsh, K. H. Ashe, J. P. Cleary, Cognitive effects of cell-derived and synthetically derived Abeta oligomers, Neurobiol Aging In Press (2011) 0.

[4] R. Sharon, I. Bar-Joseph, M. P. Frosch, D. M. Walsh, J. A. Hamilton, D. J. Selkoe, The formation of highly soluble oligomers of alpha-synuclein is regulated by fatty acids and enhanced in parkinson's disease, Neuron 37 (2003) 583-595.

[5] D. P. Karpinar, M. B. Balija, S. Kügler, F. Opazo, N. Rezaei-Ghaleh, N. Wender, H. Y. Kim, G. Taschenberger, B. H. Falkenburger, H. Heise, A. Kumar, D. Riedel, L. Fichtner, A. Voigt, G. H. Braus, K. Giller, S. Becker, A. Herzig, M. Baldus, H. Jäckle, S. Eimer, J. B. Schulz, C. Griesinger, M. Zweckstetter, Pre-fibrillar alpha-synuclein variants with impaired beta-structure increase neurotoxicity in Parkinson's disease models, EMBO J 28 (2009) 3256-3268.

[6] A. E. Butler, J. Janson, W. C. Soeller, P. C. Butler, Increased beta-cell apoptosis prevents adaptive increase in beta-cell mass in mouse model of type 2 diabetes: evidence for role of islet amyloid formation rather than direct action of amyloid, Diabetes 52 (2003) 2304-2314.

[7] C. G. Glabe, Common mechanisms of amyloid oligomer pathogenesis in degenerative disease, Neurobiol Aging 27 (2006) 570-575.

[8] S. Barghorn, V. Nimmrich, A. Striebinger, C. Krantz, P. Keller, B. Janson, M. Bahr, M. Schmidt, R. S. Bitner, J. Harlan, E. Barlow, U. Ebert, H. Hillen, Globular amyloid beta-peptide oligomer - a homogenous and stable neuropathological protein in Alzheimer's disease, J Neurochem 95 (2005) 834-847.

[9] V. Nimmrich, C. Grimm, A. Draguhn, S. Barghorn, A. Lehmann, H. Schoemaker, H. Hillen, G. Gross, U. Ebert, C. Bruehl, Amyloid beta oligomers 
(a beta(1-42) globulomer) suppress spontaneous synaptic activity by inhibition of p/q-type calcium currents, J Neurosci 28 (2008) 788-797.

[10] G. P. Gellermann, H. Byrnes, A. Striebinger, K. Ullrich, R. Mueller, H. Hillen, S. Barghorn, Abeta-globulomers are formed independently of the fibril pathway, Neurobiol Dis 30 (2008) 212-220.

[11] L. Yu, R. Edalji, J. E. Harlan, T. F. Holzman, A. P. Lopez, B. Labkovsky, H. Hillen, S. Barghorn, U. Ebert, P. L. Richardson, L. Miesbauer, L. Solomon, D. Bartley, K. Walter, R. W. Johnson, P. J. Hajduk, E. T. Olejniczak, Structural characterization of a soluble amyloid beta-peptide oligomer, Biochemistry 48 (2009) 1870-1877.

[12] K. Hasegawa, S. Tsutsumi-Yasuhara, T. Ookoshi, Y. Ohhashi, H. Kimura, N. Takahashi, H. Yoshida, R. Miyazaki, Y. Goto, H. Naiki, Growth of beta(2)-microglobulin-related amyloid fibrils by non-esterified fatty acids at a neutral pH, Biochem J 416 (2008) 307-315.

[13] R. P. Nanga, J. R. Brender, J. Xu, G. Veglia, A. Ramamoorthy, Structures of rat and human islet amyloid polypeptide IAPP(1-19) in micelles by NMR spectroscopy, Biochemistry 47 (2008) 12689-12697.

[14] S. Rodziewicz-Motowidło, P. Juszczyk, A. S. Kołodziejczyk, E. Sikorska, A. Skwierawska, M. Oleszczuk, Z. Grzonka, Conformational solution studies of the SDS micelle-bound 11-28 fragment of two Alzheimer's betaamyloid variants (E22K and A21G) using CD, NMR, and MD techniques, Biopolymers 87 (2007) 23-39.

[15] A. Wahlström, L. Hugonin, A. Perálvarez-Marín, J. Jarvet, A. Gräslund, Secondary structure conversions of Alzheimer's Abeta(1-40) peptide induced by membrane-mimicking detergents, FEBS J 275 (2008) 5117-5128.

[16] K. Wilhelm, A. Darinskas, W. Noppe, E. Duchardt, K. H. Mok, V. Vukojević, J. Schleucher, L. A. Morozova-Roche, Protein oligomerization in- 
duced by oleic acid at the solid-liquid interface-equine lysozyme cytotoxic complexes, FEBS J 276 (2009) 3975-3989.

[17] D. Thirumalai, D. K. Klimov, R. I. Dima, Emerging ideas on the molecular basis of protein and peptide aggregation, Curr Opin Struct Biol 13 (2003) 146-159.

[18] A. Caflisch, Computational models for the prediction of polypeptide aggregation propensity, Curr Opin Chem Biol 10 (2006) 437-444.

[19] B. Ma, R. Nussinov, Simulations as analytical tools to understand protein aggregation and predict amyloid conformation, Curr Opin Chem Biol 10 (2006) 445-452.

[20] N. Javid, K. Vogtt, C. Krywka, M. Tolan, R. Winter, Capturing the interaction potential of amyloidogenic proteins, Phys Rev Lett 99 (2007) 028101.

[21] S. Sharma, F. Ding, N. V. Dokholyan, Probing protein aggregation using discrete molecular dynamics, Front Biosci 13 (2008) 4795-4808.

[22] J. E. Straub, D. Thirumalai, Principles governing oligomer formation in amyloidogenic peptides, Curr Opin Struct Biol 20 (2010) 187-195.

[23] T. Takeda, W. E. Chang, E. P. Raman, D. K. Klimov, Binding of nonsteroidal anti-inflammatory drugs to Abeta fibril, Proteins 78 (2010) 28492860.

[24] R. Friedman, Aggregation of amyloids in a cellular context: modelling and experiment, Biochem. J 438 (2011) 415-26.

[25] M. K. Gilson, S. E. Radford, Protein folding and binding: from biology to physics and back again, Curr Opin Struct Biol 21 (2011) 1-3.

[26] J. E. Shea, Coarse-grained models for protein aggregation, Curr Opin Struct Biol 21 (2011) 209-220. 
[27] R. Pellarin, A. Caflisch, Interpreting the aggregation kinetics of amyloid peptides, J Mol Biol 360 (2006) 882-892.

[28] R. Pellarin, E. Guarnera, A. Caflisch, Pathways and intermediates of amyloid fibril formation, J Mol Biol 374 (2007) 917 - 924.

[29] R. Pellarin, P. Schuetz, E. Guarnera, A. Caflisch, Amyloid fibril polymorphism is under kinetic control, J Am Chem Soc 132 (2010) 14960-14970.

[30] R. Friedman, R. Pellarin, A. Caflisch, Amyloid aggregation on lipid bilayers and its impact on membrane permeability, J Mol Biol 387 (2009) 407-415.

[31] A. Magno, R. Pellarin, A. Caflisch, Crowding effects on amyloid aggregation kinetics, J Phys Chem Lett 1 (2010) 3027-3032.

[32] D. Tsao, A. P. Minton, N. V. Dokholyan, A didactic model of macromolecular crowding effects on protein folding, PLoS One 5 (2010) e11936.

[33] E. P. O'Brien, J. E. Straub, B. R. Brooks, D. Thirumalai, Influence of nanoparticle size and shape on oligomer formation of an amyloidogenic peptide, J Chem Phys Lett 2 (2011) 1171-1177.

[34] K. Dahse, M. Garvey, M. Kovermann, A. Vogel, J. Balbach, M. Fändrich, A. Fahr, DHPC strongly affects the structure and oligomerization propensity of alzheimer's A $\beta(1-40)$ peptide, J Mol Biol 403 (2010) 643-659.

[35] K. K. Andersen, C. L. Oliveira, K. L. Larsen, F. M. Poulsen, T. H. Callisen, P. Westh, J. S. Pedersen, D. Otzen, The role of decorated SDS micelles in sub-CMC protein denaturation and association, J Mol Biol 391 (2009) $207-226$.

[36] L. Giehm, C. L. Oliveira, G. Christiansen, J. S. Pedersen, D. E. Otzen, SDSinduced fibrillation of alpha-synuclein: an alternative fibrillation pathway, J Mol Biol 401 (2010) 115-133.

[37] J. H. van Esch, Supramolecular chemistry: More than the sum of its parts, Nature 466 (2010) 193-194. 
[38] F. E. Antunes, E. F. Marques, M. G. Miguel, B. Lindman, Polymer-vesicle association, Adv. In Colloid Interface Science 147-48 (2009) 18-35.

[39] R. Friedman, E. Nachliel, M. Gutman, Molecular dynamics of a protein surface: Ion-residues interactions, Biophys. J. 89 (2005) 768-81.

[40] H. Meirovitch, Methods for calculating the absolute entropy and free energy of biological systems based on ideas from polymer physics, J Mol Recognit 23 (2010) 153-172.

[41] R. A. Böckmann, A. Caflisch, Spontaneous formation of detergent micelles around the outer membrane protein OmpX, Biophys J 88 (2005) 31913204 .

[42] M. Cecchini, R. Curcio, M. Pappalardo, R. Melki, A. Caflisch, A molecular dynamics approach to the structural characterization of amyloid aggregation, J Mol Biol 357 (2006) 1306-1321.

[43] L. S. Wolfe, M. F. Calabrese, A. Nath, D. V. Blaho, A. D. Miranker, Y. Xiong, Protein-induced photophysical changes to the amyloid indicator dye thioflavin T, Proc Natl Acad Sci U S A 107 (2010) 16863-16868.

[44] T. Kajiyama, Y. Oishi, M. Uchida, Y. Tanimoto, H. Kozuru, Morphological and structural studies of crystalline and amorphous monolayers on the water-surface, Langmuir 8 (1992) 1563-1569.

[45] R. Friedman, R. Pellarin, A. Caflisch, Soluble protofibrils as metastable intermediates in simulations of amyloid fibril degradation induced by lipid vesicles, J Phys Chem Lett 1 (2010) 471-474.

[46] B. R. Brooks, R. E. Bruccoleri, B. D. Olafson, D. J. States, S. Swaminathan, M. Karplus, CHARMM: A program for macromolecular energy, minimization, and dynamics calculations, J. Comp. Chem. 4 (1983) 187217. 
[47] B. R. Brooks, C. L. Brooks, A. D. MacKerell, L. Nilsson, B. Roux, Y. Won, G. Archontis, C. Bartels, S. Boresch, A. Caflisch, L. Caves, Q. Cui, A. Dinner, S. Fischer, J. Gao, M. Hodoscek, K. Kuczera, T. Lazaridis, J. Ma, E. Paci, R. W. Pastor, C. B. Post, M. Schaefer, B. Tidor, R. W. Venable, H. L. Woodcock, X. Wu, M. Karplus, CHARMM: The biomolecular simulation program, J. Comp. Chem. 30 (2009) 1545-614.

[48] J.-P. Ryckaert, G. Ciccotti, H. J. C. Berendsen, Numerical integration of the cartesian equations of motion of a system with constraints: Molecular dynamics of n-alkanes, J Comput Phys 23 (1977) 327-341.

[49] M. Seeber, M. Cecchini, F. Rao, G. Settanni, A. Caflisch, Wordom: a program for efficient analysis of molecular dynamics simulations, Bioinformatics 23 (2007) 2625-2627.

[50] M. Seeber, A. Felline, F. Raimondi, S. Muff, R. Friedman, F. Rao, A. Caflisch, F. Fanelli, Wordom: a user-friendly program for the analysis of molecular conformations, trajectories, and free energy surfaces, J Comput Chem 32 (2011) 1183-1194.

[51] W. Humphrey, A. Dalke, K. Schulten, VMD: visual molecular dynamics, J. Mol. Graph. 14 (1996) 33-38. 
Tables and Figures

\begin{tabular}{llllll}
\hline $\begin{array}{l}\mathrm{R}_{\text {hydrophilic }} \\
(\mathrm{nm})\end{array}$ & $\begin{array}{l}\mathrm{R}_{\text {hydrophobic }} \\
(\mathrm{nm})\end{array}$ & $\begin{array}{c}\epsilon_{\text {hydrophilic }} \\
(\mathrm{kcal} / \mathrm{mol})\end{array}$ & $\begin{array}{l}\epsilon_{\text {hydrophobic }} \\
(\mathrm{kcal} / \mathrm{mol})\end{array}$ & $\lambda^{a}$ & Reference \\
\hline 0.35 & 0.3 & -0.1 & -0.8 & 1 & this work \\
0.31 & 0.3 & -0.1 & -1.265 & $0.87-0.90$ & {$[30]$} \\
0.31 & 0.3 & -0.1 & -1.265 & 0.95 & {$[45]$} \\
\hline
\end{tabular}

Table 1: Three-bead lipid and surfactant models used in coarse-grained simulations with aggregating peptides in this and previous works. ${ }^{a}$ Scaling factor for the vdW interactions between lipids or surfactants and peptides. Different values of $\lambda$ are used to model different systems, i.e., surfactants $(\lambda=1)$, moderately attractive lipid bilayers $(\lambda \leq 0.9)$ and strongly attractive lipid bilayers $(\lambda \approx 0.95)$. 


\begin{tabular}{llrrrlc}
\hline $\begin{array}{l}\mathrm{dE} \\
(\mathrm{kcal} / \mathrm{mol})\end{array}$ & $\begin{array}{l}\text { Number of } \\
\text { peptides }\end{array}$ & $\begin{array}{r}\text { Number of } \\
\text { surfactants }\end{array}$ & $\begin{array}{r}\text { Number of } \\
\text { simulations }\end{array}$ & $\begin{array}{r}\text { Simulation } \\
\operatorname{time}(\mu \mathrm{s})\end{array}$ & $\begin{array}{l}\mathrm{t}_{l p}^{a} \\
(\mathrm{~ns})\end{array}$ & $\begin{array}{l}\mathrm{k}_{e}^{b} \\
\left(\mu \mathrm{s}^{-1}\right)\end{array}$ \\
\hline-1.5 & 125 & 0 & 97 & 1.45 & $6.5 \pm 11$ & $11.7 \pm 1.7$ \\
& 125 & 1000 & 20 & 2 & 0.01 & $8.6 \pm 2.3$ \\
-2.0 & 125 & 0 & 99 & 1.45 & $28 \pm 27$ & $7.7 \pm 1.9$ \\
& 125 & 500 & 20 & 2 & $78 \pm 53$ & $8.2 \pm 2.4$ \\
& 125 & 1000 & 20 & 2 & no fibrillation \\
-2.25 & 125 & 0 & 100 & 2 & $122 \pm 135$ & $4.8 \pm 1.4$ \\
& 125 & 500 & 16 & 8 & $1860 \pm 2150$ & $5.8 \pm 3.0$ \\
& 125 & 1000 & 20 & 2 & no fibrillation \\
\hline
\end{tabular}

Table 2: Details of the coarse-grained simulations. The simulations without surfactants were carried out previously $[27,30] .{ }^{a}$ Length of the lag phase. ${ }^{b}$ Elongation rate. For the definition and details on the calculation of $\mathrm{t}_{l p}$ and $\mathrm{k}_{e}$ see Ref. [27].

\begin{tabular}{lcccl}
\hline \multirow{2}{*}{$\mathrm{dE}$} & surfactant:peptide & \multicolumn{3}{c}{ Largest aggregate } \\
\cline { 3 - 5 }$(\mathrm{kcal} / \mathrm{mol})$ & ratio & $\mathrm{N}_{\text {peptides }}$ & $\mathrm{N}_{\text {surfactants }}$ & type \\
\hline-1.5 & $8: 1$ & $113 \pm 4$ & $120 \pm 60$ & fibril \\
-2.0 & $8: 1$ & $38 \pm 16$ & $166 \pm 7$ & globular aggregate \\
-2.25 & $8: 1$ & $38 \pm 16$ & $163 \pm 7$ & globular aggregate \\
& & & & \\
-2.0 & $4: 1$ & $105 \pm 7$ & $16 \pm 6$ & fibril \\
-2.25 & $4: 1$ & $95 \pm 9$ & $14 \pm 5$ & fibril \\
& & $20 \pm 10$ & $16 \pm 7$ & metastable oligomer \\
\hline
\end{tabular}

Table 3: Average numbers of peptides and surfactants in the largest aggregate at the end of the simulations. ${ }^{a}$ The simulations with $\mathrm{dE}=-2.25 \mathrm{kcal} / \mathrm{mol}$ and surfactant:peptide ratio 4:1 show a mixed oligomer which dissolves within $8 \mu$ s in 15 of the 16 runs. 


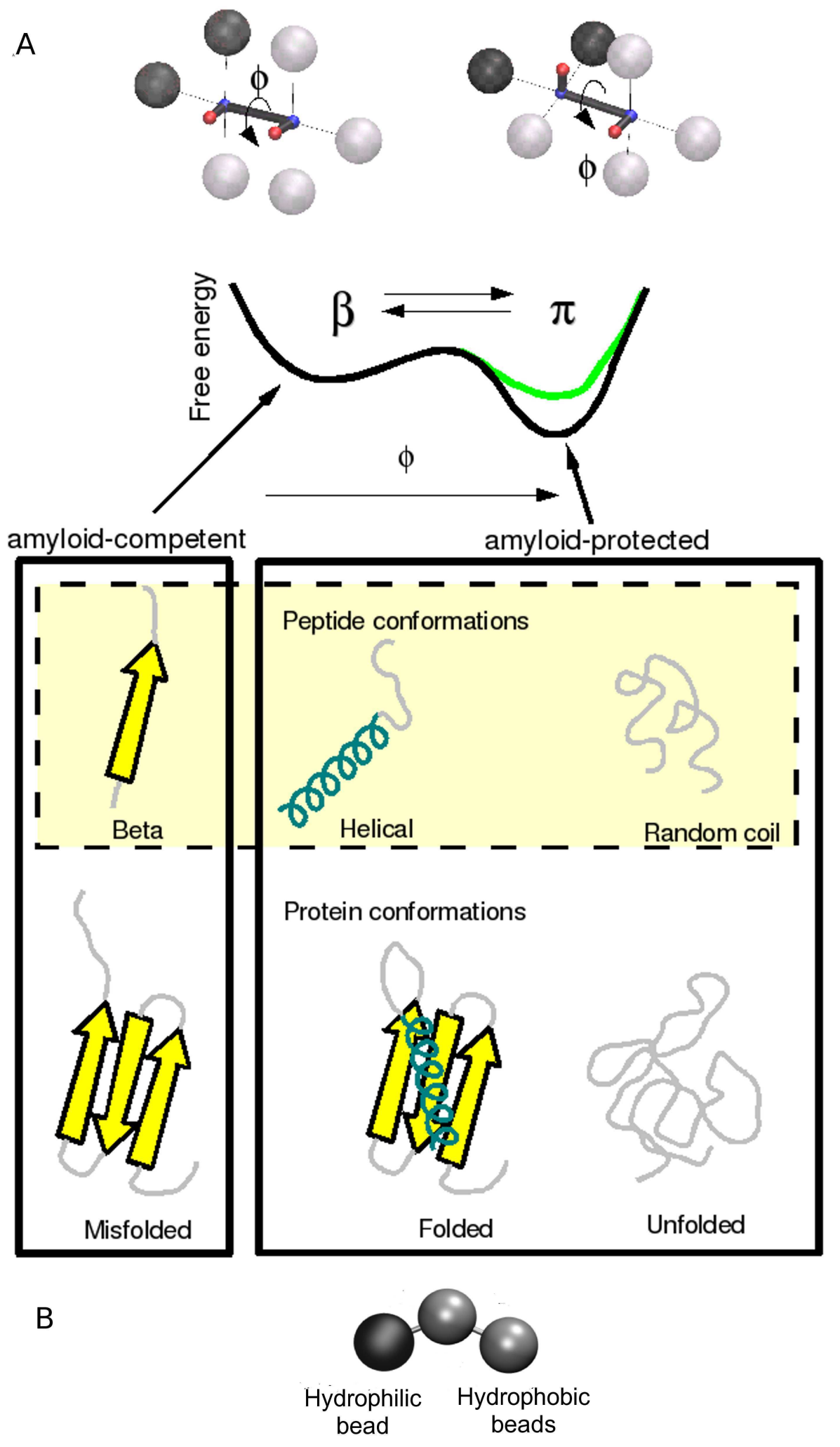

Figure 1: (Caption on next page). 
Figure 1: Peptide and surfactant models. (A) Simplified peptide model. Sticks and beads representation of the monomer in the amyloid competent state $\beta$ and the amyloid protected state $(\pi)$. The large spheres are hydrophobic (black) and hydrophilic (gray), while the two dipoles are shown with small red and blue spheres. The interpeptide interaction energy consists of a van der Waals term and a Coulombic term, both with a cutoff of $2 \mathrm{~nm}$. The van der Waals term has a more pronounced, i.e., more favorable, minimum energy for the two hydrophobic spheres than the remaining eight spheres. The Coulombic term is used for the dipole-dipole interactions. The $\beta$ and $\pi$ states of the monomer are shown on top of the two corresponding minima of the free energy plotted as a continuous function of the dihedral angle $\phi$ of the two dipoles. Note that the population of monomers in the $\beta$-state decreases by lowering the free energy of the $\pi$-state, as indicated by the green and black profiles. In the $\beta$-state, the parallel orientation of the two intramolecular dipoles favors ordered aggregates, with intermolecular dipolar interactions parallel to the fibrillar axis. Conversely, the $\pi$-state represents the ensemble of all polypeptide conformations that are not compatible with self-assembly into a fibril. Reprinted with permission from [28]. (B) Coarse-grained model of surfactant. The length of the two bonds is $0.7 \mathrm{~nm}$ and the angle between the three beads is $134^{\circ}$. The beads do not bear any partial charges. The bonds are constrained by the SHAKE algorithm [48], and the angle is kept close to its ideal value by an harmonic potential with a force constant of $100 \mathrm{kcal} \mathrm{mol}^{-1}$ degree $^{-1}$. Non-bonded attraction and repulsion are modeled by the 6-12 van der Waals energy term (parameters listed in Table 1) with a cutoff of $2 \mathrm{~nm}$. 




Figure 2: Peptide aggregation kinetics in the presence and absence of surfactants.

The number of peptides in the largest aggregate is averaged over 20 runs at each simulation condition, i.e., for each value of aggregation propensity $(\mathrm{dE})$ and each surfactant:peptide concentration ratio. Fast aggregation without any noticeable lag phase is observed in the absence of surfactants. At surfactant:peptide ratio of 4:1, the aggregation kinetics are slow for peptides with low amyloidogenicity (for $\mathrm{dE}=-2.25$ see the inset with the full simulation length up to $8 \mu \mathrm{s})$. At surfactant:peptide ratio of 8:1, aggregation is completely inhibited for $\mathrm{dE}=-2.0$ and $-2.25 \mathrm{kcal} / \mathrm{mol}$, while highly amyloidogenic peptides $(\mathrm{dE}=-1.5 \mathrm{kcal} / \mathrm{mol})$ are barely affected. 

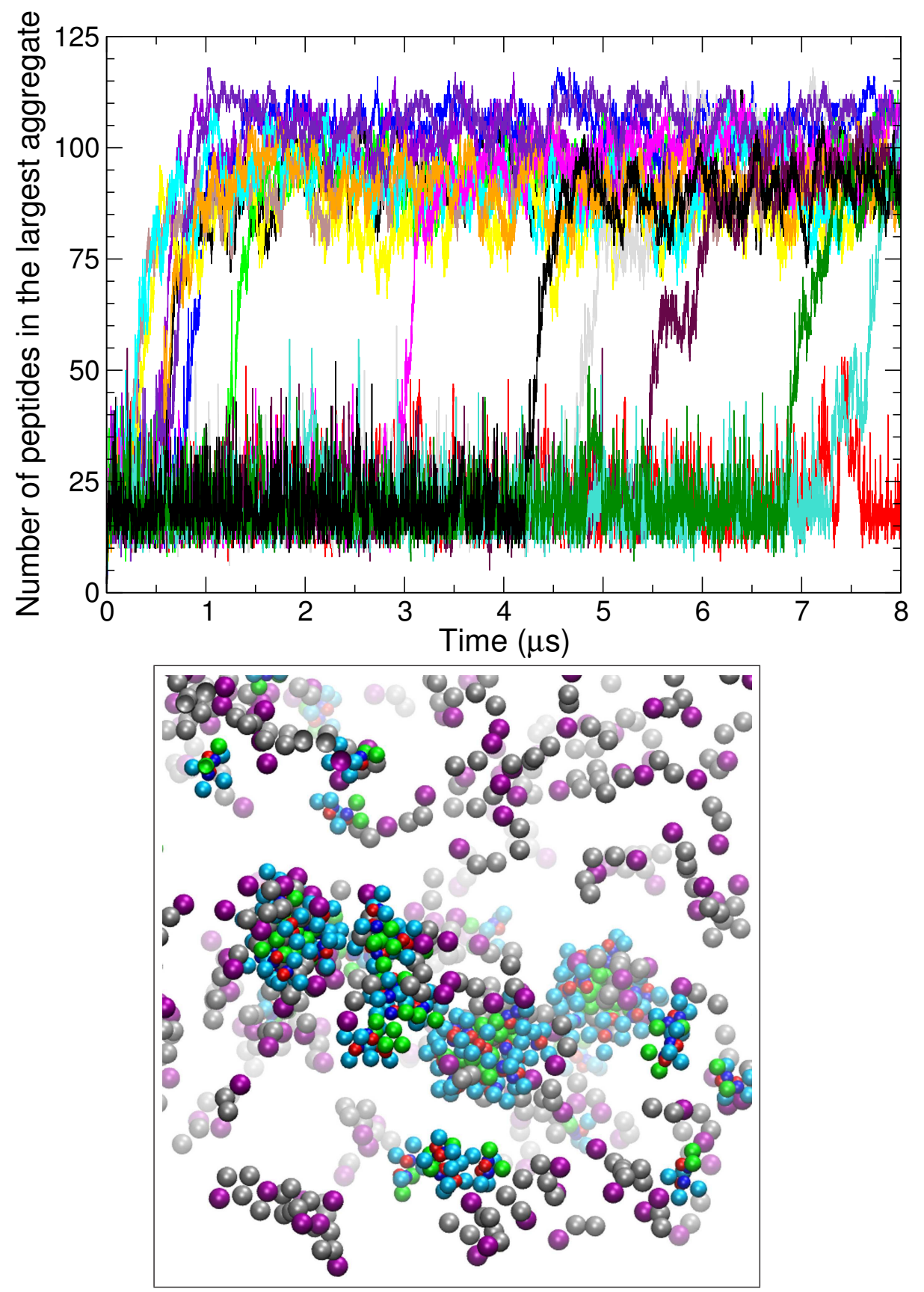

Figure 3: Fibril formation kinetics in the presence of surfactants. (Top) The number of peptides in the largest cluster is shown as a function of simulation time for the 16 runs with $\mathrm{dE}=-2.25 \mathrm{kcal} / \mathrm{mol}$ and surfactant:peptide ratio $4: 1$. Each run is shown with a different color. The lag phase has variable length because fibril nucleation is a stochastic process. In one of the 16 runs (red curve) fibril formation does not take place within the $8 \mu$ s simulation length. (Bottom) Mixed oligomers are responsible for a longer lag phase in the presence of surfactants for peptides with low amyloidogenic propensity. This representative snapshot was taken from a simulation with $\mathrm{dE}=-2.25 \mathrm{kcal} / \mathrm{mol}$ and surfactant:peptide ratio 4:1. The lipids are displayed with the hydrophilic head group in magenta and the two hydrophobic beads in gray. The peptide hydrophilic and hydrophobic beads are in cyan and green, respectively, while the dipoles are in blue and red. 


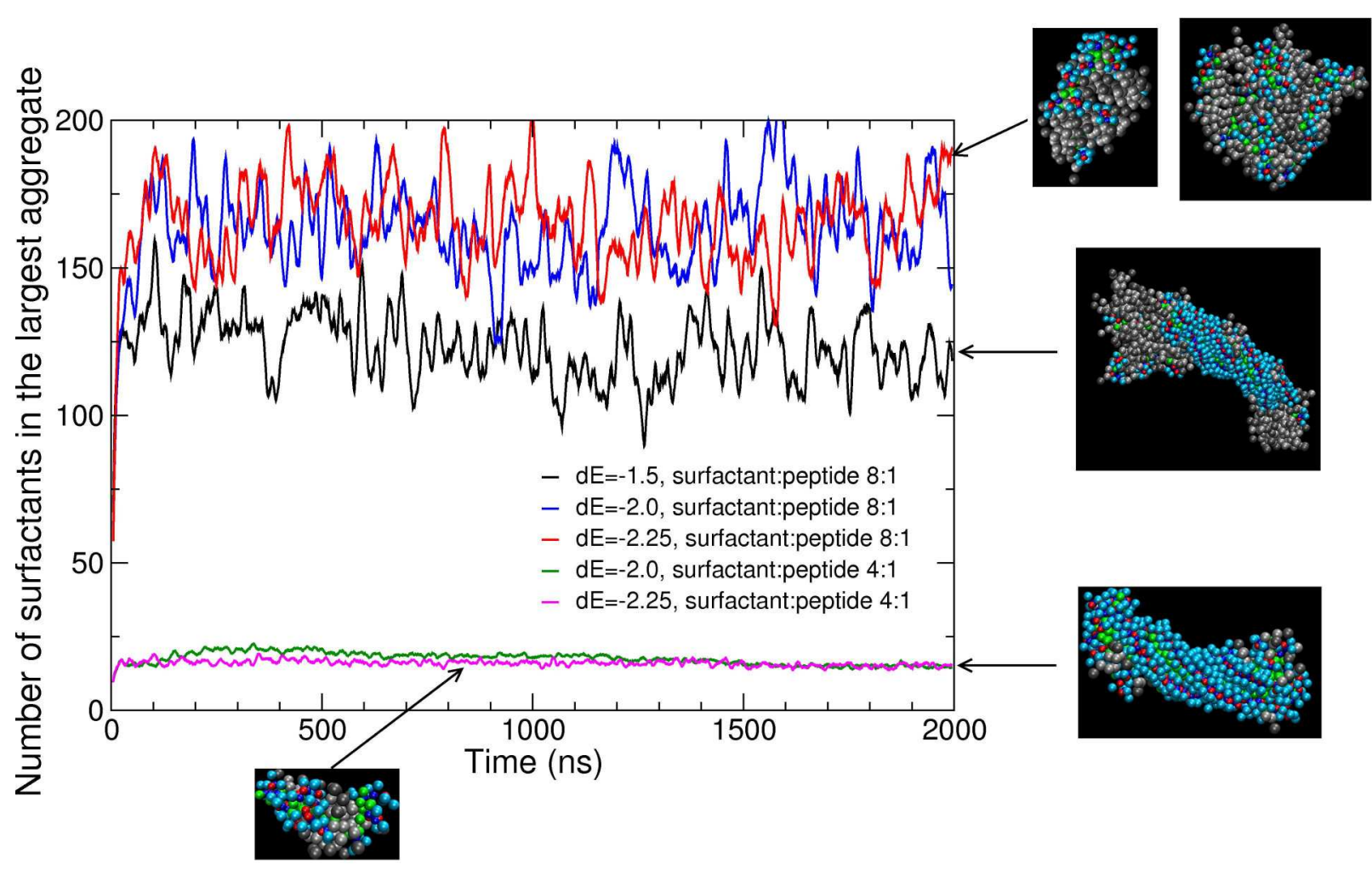

Figure 4: Surfactants are part of the peptide aggregates. The time series of the average number of surfactants attached to the largest cluster of molecules were averaged over all runs at each condition. Representative illustrations of mixed micelles and fibrils are shown with peptide hydrophilic and hydrophobic beads in cyan and green, respectively, peptide dipoles in blue/red, and surfactant beads in gray. 


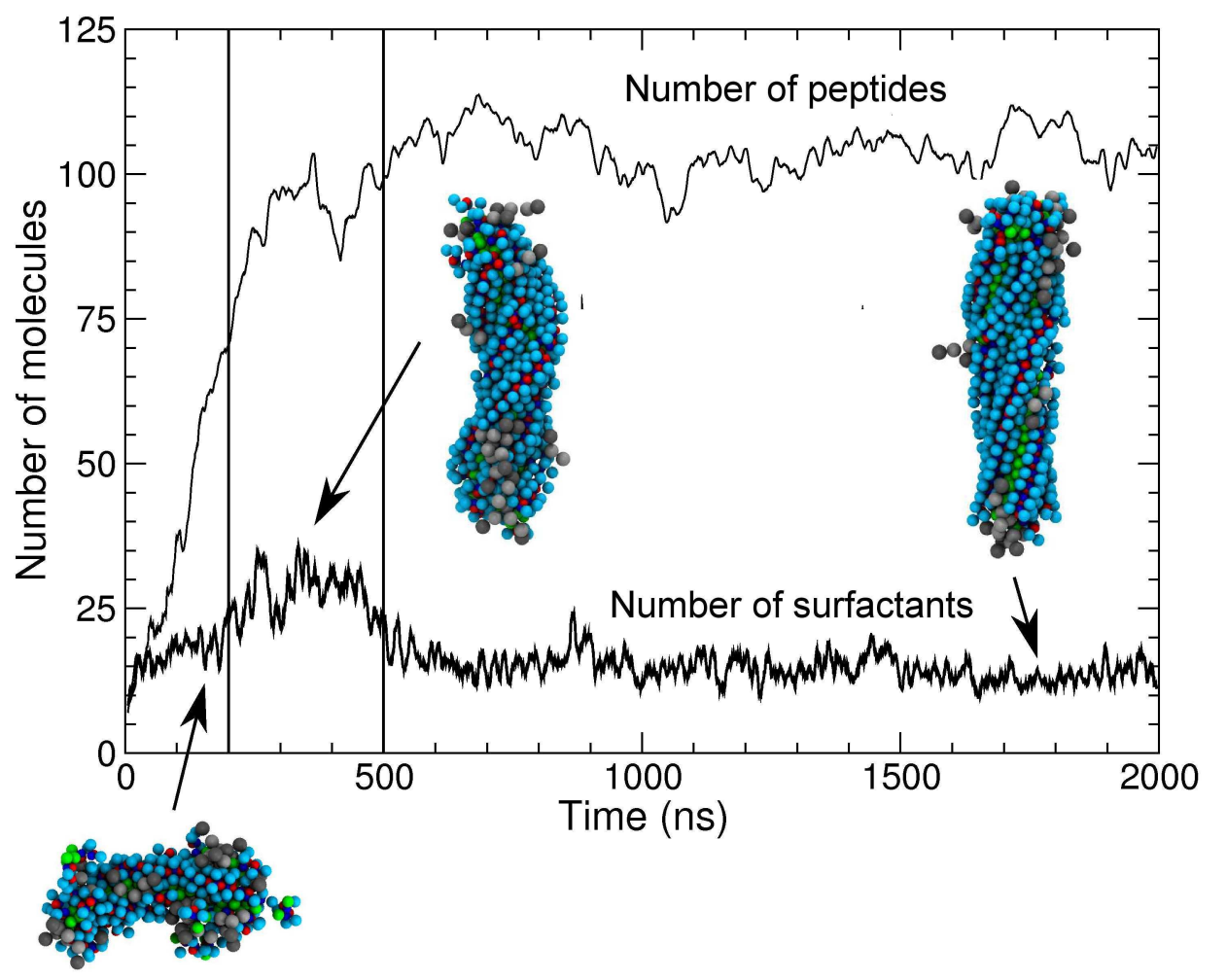

Figure 5: Transient peak of the number of surfactants. The number of peptides (thin lines) and surfactants (thick lines) are shown for a simulation with $\mathrm{dE}=-2.0 \mathrm{kcal} / \mathrm{mol}$ and a 4:1 surfactant:peptide ratio. The time series of the number of surfactants on the largest aggregate has a peak (emphasized by vertical lines) during fibril growth before reaching the final mature fibril. The three snapshots shown as insets represent the nucleus, fibril growth with transient peak of surfactants, and mature fibril. Note that the surfactants (gray beads) bind at exposed hydrophobic patches of the peptide oligomers and (proto)fibril. The protofibril structure that represents the transient peak of surfactants shows at its bottom part a large hydrophobic patch buried by about 10 surfactants. 

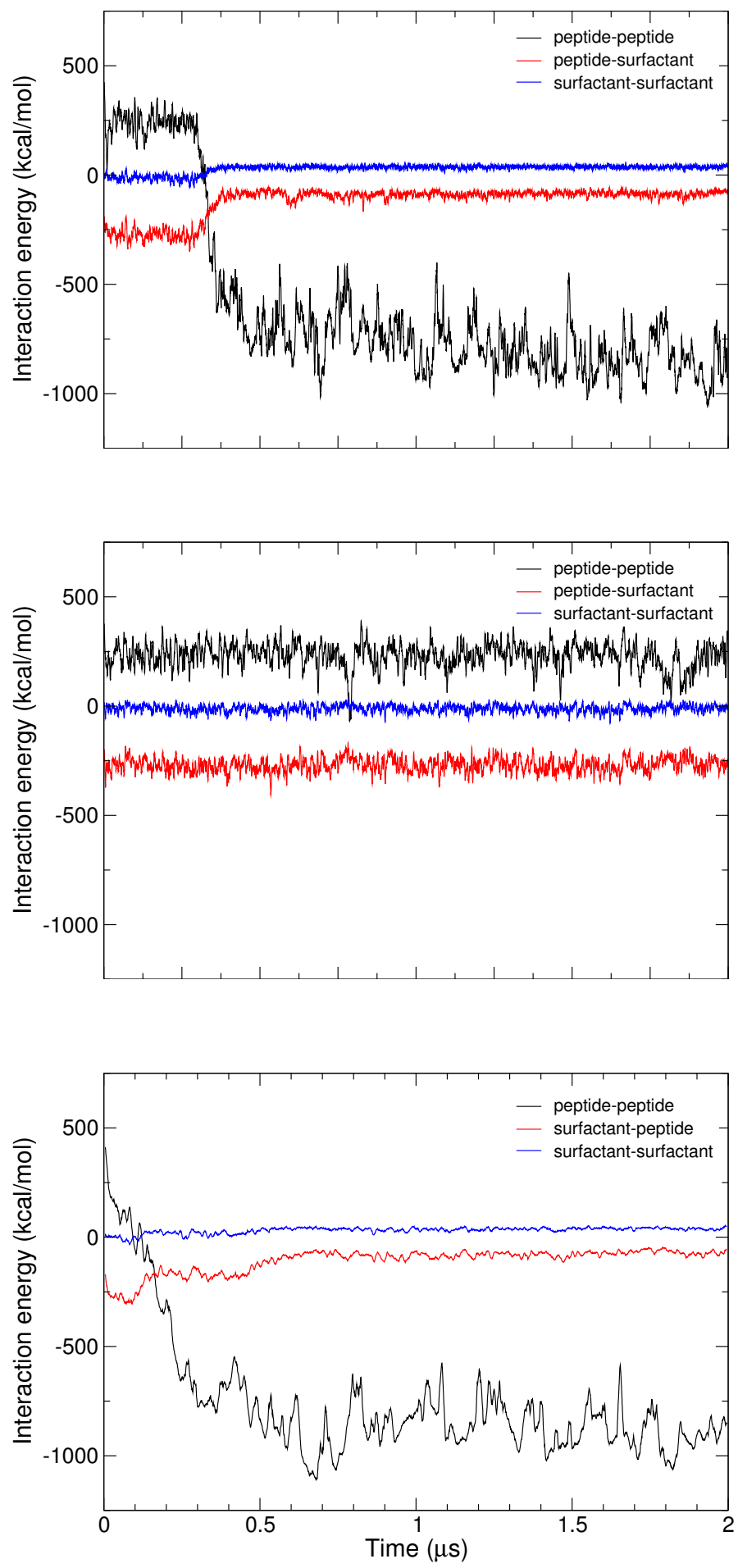

Figure 6: Interaction energies between peptides and surfactants. Time series of the total peptide-peptide (black), peptide-surfactant (red) and surfactant-surfactant (blue) interaction energies are shown for three representative simulations. Note that the peptidepeptide interactions are the sum of van der Waals and Coulombic terms while the peptidesurfactant and surfactant-surfactant interactions are only van der Waals as only the coarsegrained peptide bears partial charges, which are located on two dipoles on each peptide (see also caption of Figure 1). (Top) Low amyloidogenicity, i.e., $\mathrm{dE}=-2.25 \mathrm{kcal} / \mathrm{mol}$ : a simulation where a fibril is formed. (Middle) Low amyloidogenicity, i.e., $\mathrm{dE}=-2.25 \mathrm{kcal} / \mathrm{mol}$ : a simulation where fibril formation does not take place and the system is dominated by mixed peptidesurfactant oligomers. (Bottom) Medium amyloidogenicity, i.e., $\mathrm{dE}=-2.0 \mathrm{kcal} / \mathrm{mol}$. Note the different $\mathrm{x}$-axis range. 


\title{
Supporting Material for: Surfactant effects on amyloid aggregation kinetics
}

\author{
Ran Friedman ${ }^{a b *}$ and Amedeo Caflisch ${ }^{a *}$
}

${ }^{a}$ University of Zürich, Department of Biochemistry, Winterthurerstrasse 190, 8057 Zürich, Switzerland ${ }^{b}$ Linnceus University, School of Natural Sciences, 39182 Kalmar, Sweden.

*corresponding authors, e-mail: ran.friedman@lnu.se, caflisch@bioc.uzh.ch 

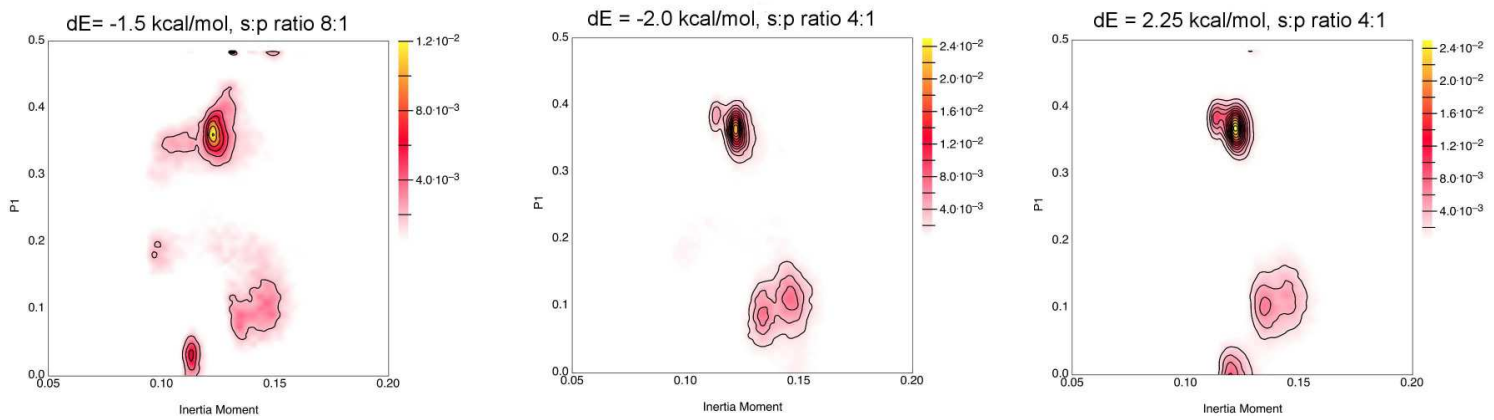

Figure S1: Quantification of fibril morphologies. Two-dimensional frequency histograms of the order parameter P1 and the minimum inertia moment (both described in Ref. [1]) calculated for the runs at $\mathrm{dE}=-1.5 \mathrm{kcal} / \mathrm{mol}$ and surfactant:peptide ratio $8: 1$ (left), $\mathrm{dE}=-$ $2.0 \mathrm{kcal} / \mathrm{mol}$ and 4:1 (middle), and $\mathrm{dE}=-2.25 \mathrm{kcal} / \mathrm{mol}$ and $4: 1$ (right). Highest frequency is colored in yellow. The Figures can be compared with Figure S3 of [1]. Apparently, the morphologies of the fibrils are not effected by the presence of surfactants. The lack of a peak corresponding to a relatively rare morphology (4PF3) for the simulation at $\mathrm{dE}=-2.0 \mathrm{kcal} / \mathrm{mol}$ is likely due to the smaller number of runs (20 simulations here and 100 in Ref. [1]). 

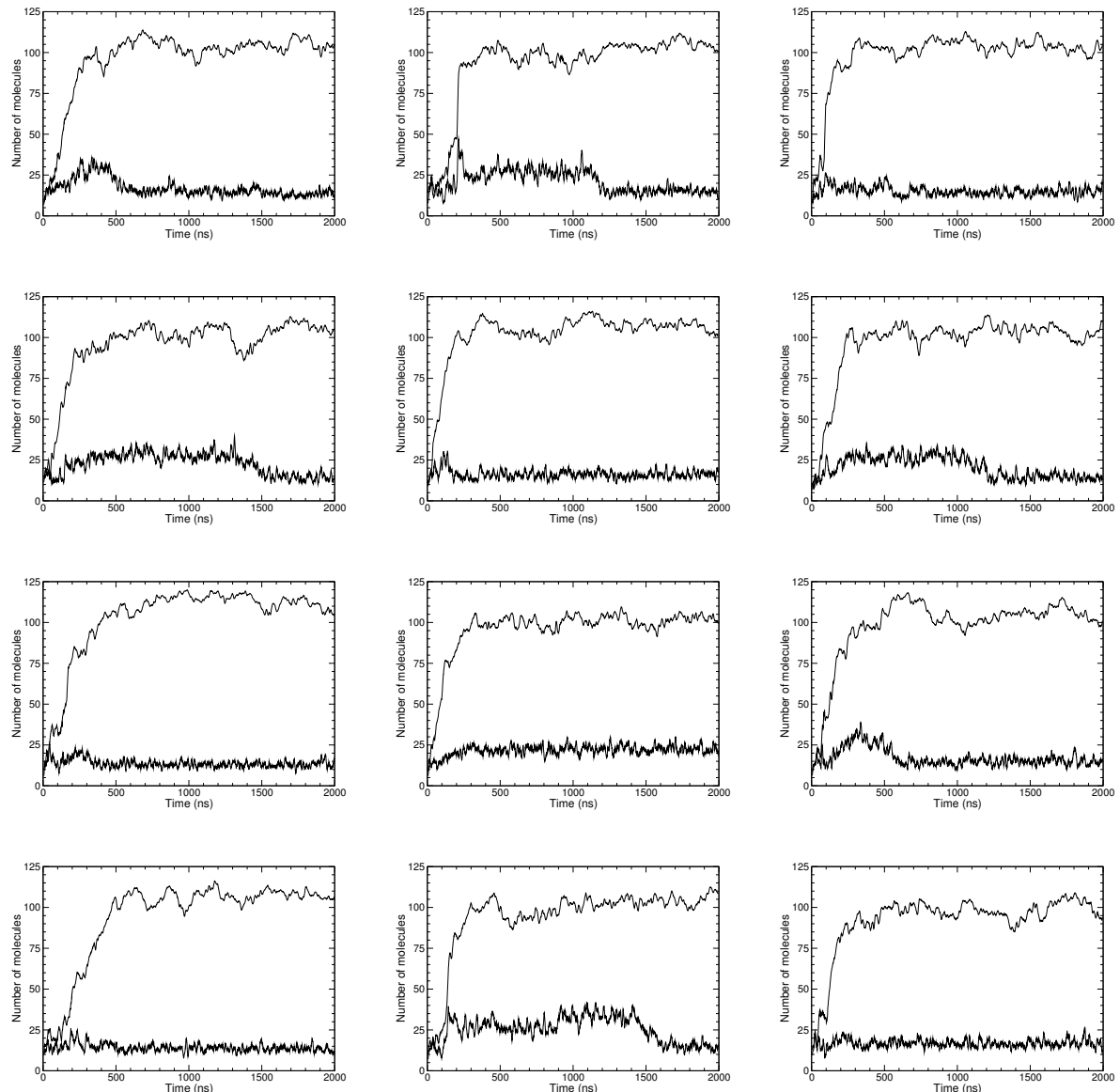

Figure S2: Temporal evolution of number of molecules in the largest cluster $(\mathrm{dE}=-$ $2.0 \mathrm{kcal} / \mathbf{m o l}$ ). The number of peptides (thin lines) and surfactants (thick lines) in the largest cluster, i.e., globulomer or fibril, are shown for all simulations with $\mathrm{dE}=-2.0 \mathrm{kcal} / \mathrm{mol}$ and 4:1 surfactant:peptide ratio. 

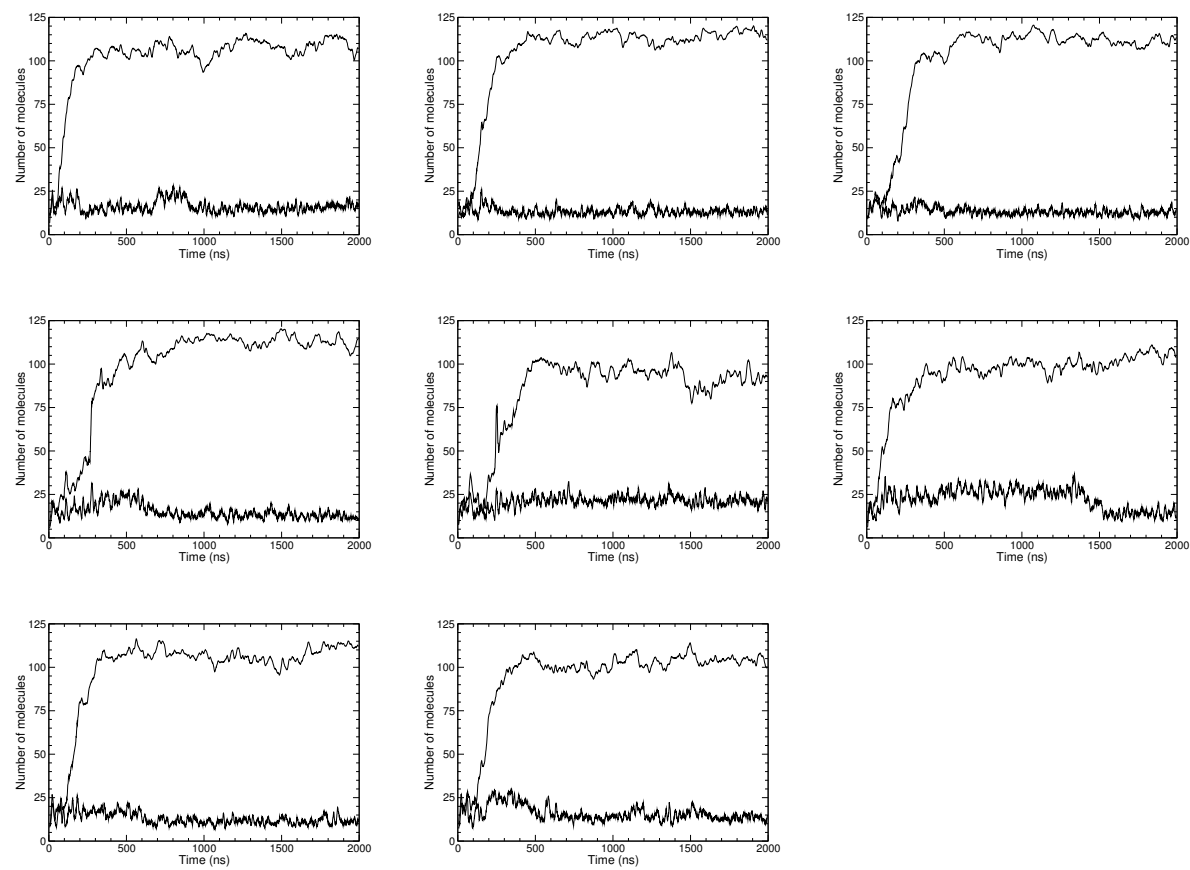

Figure S2 (continued) 

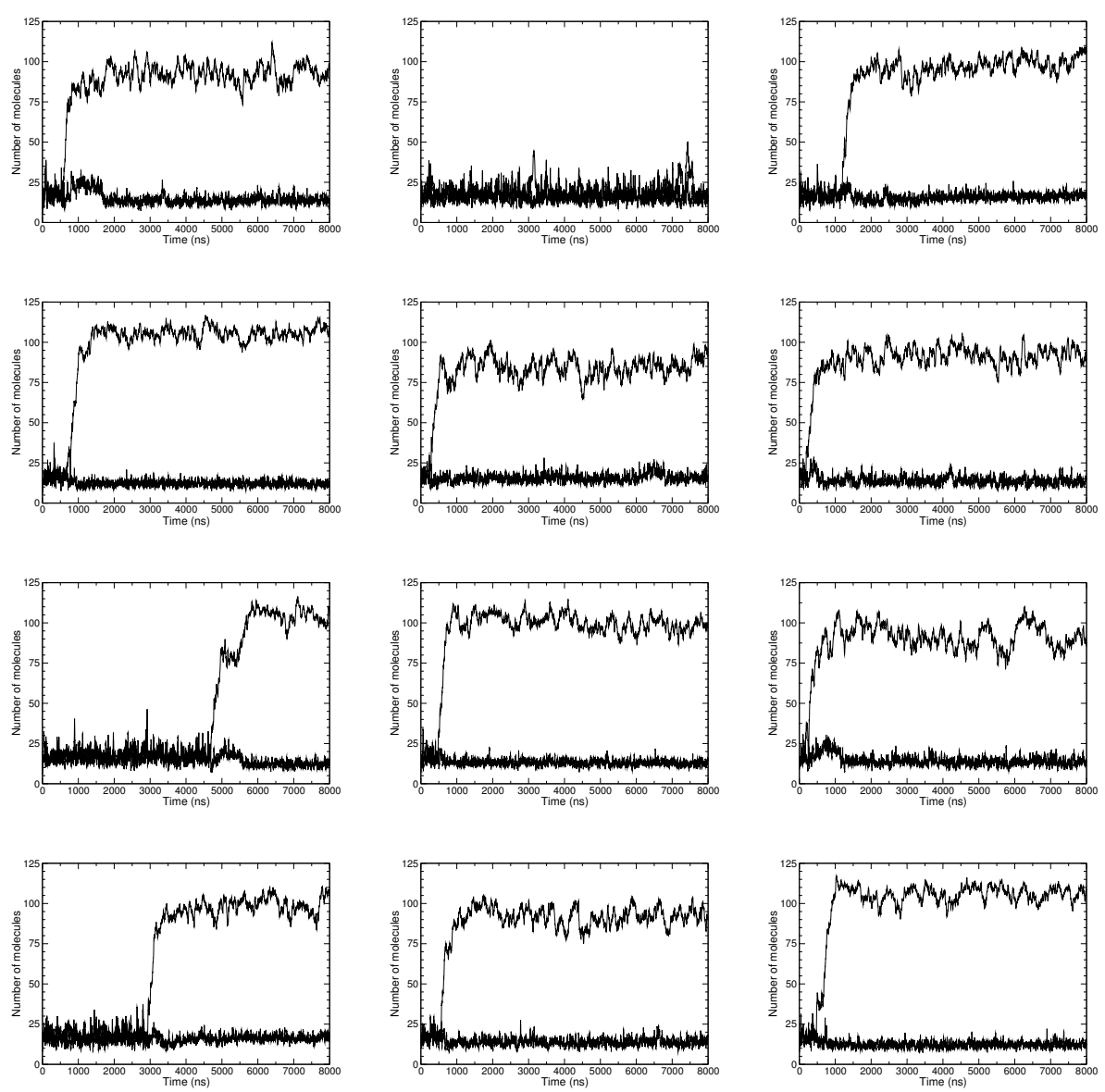

Figure S3: Temporal evolution of number of molecules in the largest cluster $(\mathrm{dE}=-$ $2.25 \mathrm{kcal} / \mathbf{m o l}$ ). The number of peptides (thin lines) and surfactants (thick lines) in the largest cluster, i.e., globulomer or fibril, are shown for all simulations with $\mathrm{dE}=-2.25 \mathrm{kcal} / \mathrm{mol}$ and 4:1 surfactant:peptide ratio. Fibril formation does not take place in one of the 16 runs (top, middle panel), and in a few cases the fibrils do not reach their finite size after $8 \mu \mathrm{s}$. Note the difference in the $\mathrm{x}$-axis scale in comparison to Figure S2. 

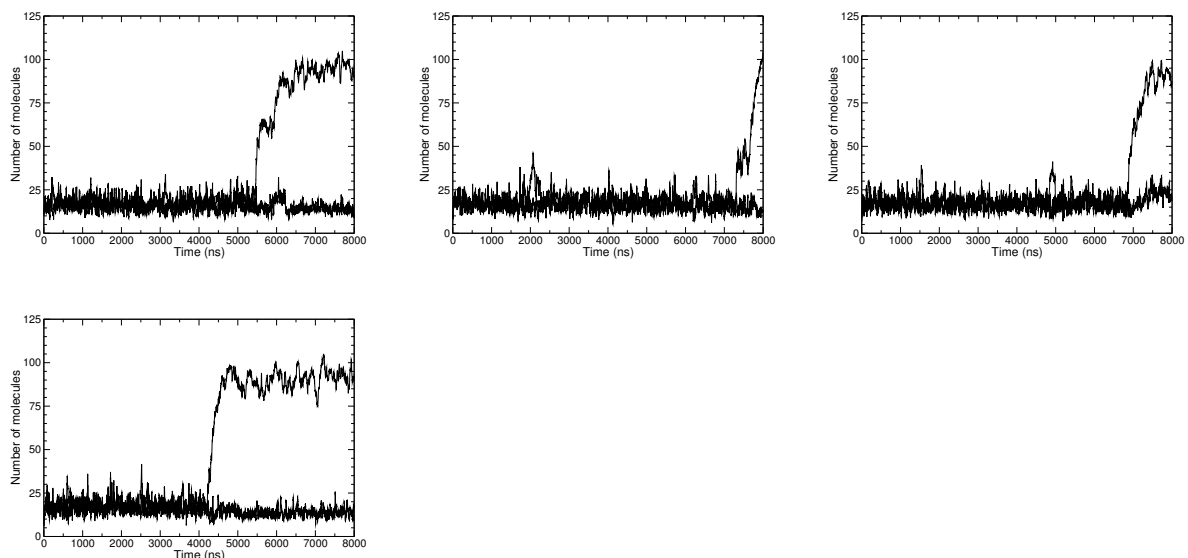

Figure S3 (continued) 
[1] R. Pellarin, P. Schuetz, E. Guarnera, A. Caflisch, Amyloid fibril polymorphism is under kinetic control, J Am Chem Soc 132 (2010) 14960-14970. 